\title{
Difficult airway prediction in paediatric anaesthesia (Diffair): Prospective observational study
}

\author{
Jozef Klucka ${ }^{a \sharp}$, Martina Kosinova ${ }^{a \#}$, Milan Kratochvila, Lukas Marecek ${ }^{\mathrm{a}}$, Petra Kovalcikova ${ }^{\mathrm{b}}$, Milan Urikc, Petr Stourac ${ }^{\mathrm{a}}$
}

Background. The incidence of difficult airway in paediatric patients is lower than that the adult population, and the majority should be predictable.

Aims. The primary aim of this trial was to evaluate the incidence of difficult airway in pediatric patients. The secondary aim was to predict difficult airway in these patients.

Methods. Paediatric patients undergoing elective surgery under general anaesthesia in a tertiary university hospital were examined, and a panel of difficult airway prediction tests was performed. We recorded the incidence, risk factors for difficult airway and events associated with difficult airway together with the sensitivity and specificity of tests for difficult airway and events associated with difficult airway prediction.

Results. We prospectively included 389 paediatric patients. The incidence of difficult airway was $3.6 \%$; the incidence of events associated with difficult airway was $10 \%$. The sensitivity for prediction of events associated with difficult airway during the pre-anaesthesia evaluation was $5.3 \%$ with the specificity $93.3 \%$. In the operating room, the sensitivity of prediction was $15 \%$ with $97.8 \%$ specificity.

Conclusion. We found minimal efficacy for preanaesthesia difficult airway prediction.

Key words: difficult airway, paediatric, prediction

Received: February 13, 2020; Revised: April 25, 2020; Accepted: April 29, 2020; Available online: May 18, 2020

https://doi.org/10.5507/bp.2020.020

(c) 2021 The Authors; https://creativecommons.org/licenses/by/4.0/

${ }^{a}$ Department of Paediatric Anaesthesiology and Intensive Care Medicine, University Hospital Brno and Faculty of Medicine, Masaryk University, Brno, Czech Republic

bInstitute of Biostatistics and Bioanalyses, Faculty of Medicine, Masaryk University, Brno, Czech Republic

'Department of Paediatric Otorhinolaryngology, University Hospital and Faculty of Medicine, Masaryk University, Brno, Czech Republic

"These authors contributed equally to this manuscript

Corresponding author:Petr Stourac, e-mail:petr.stourac@gmail.com

\section{INTRODUCTION}

Difficult airways and failure to ventilate and oxygenate the patient is strongly connected with significant morbidity and mortality of both adult and paediatric patients ${ }^{1-4}$. The ideal timing for airway management planning is the outpatient pre-anaesthesia evaluation. The airway evaluation should be based on a patient's history and results of clinical examination using a combination of several tests for difficult airway prediction. The most frequently used prediction tests with reported good effectivity are: Mallampati score, upper lip bite test, cervical spine mobility and thyromental distance (measured in the fold of the patient's fingers $)^{5-7}$. Age $<1$ year, ASA III-IV classification, Mallampati III-IV score, obesity (BMI $\geq 35$ ), ENT and cardiac surgery patient belongs to risk factors for difficult airways $^{6-9}$.

Difficult airway (DA) is a heterogeneous group that can be divided by the origin of the difficulty: difficult mask ventilation, difficult supraglottic airway insertion, difficult laryngoscopy, difficult intubation and cannot intubate/ cannot oxygenate (CICO) scenario ${ }^{10}$. DA is however not precisely defined, and therefore Apfelbaum et al. ${ }^{11}$ in cooperation with the American society of Anesthesiology tried to redefine DA as Difficult face mask or supraglottic device ventilation in the situation in which a conventionally trained anaesthesiologist is not capable of achieving adequate ventilation and oxygenation ${ }^{11}$. Difficult supraglottic device insertion and difficult tracheal intubation are defined by the number of attempts needed for effective airway management - the cut-off in the majority of published data is set at 3 attempts ${ }^{11-12}$. The published DA incidence in paediatric patients is lower than in adults (difficult face mask ventilation 2.8-6.6\%, difficult laryngoscopy $0.06-1.34 \%$ ) and should be easier to predict ${ }^{13}$. This trial aimed to evaluate the incidence of DA in a selected cohort of patients and to evaluate the options for DA prediction.

\section{MATERIALS AND METHODS}

After approval by the local Ethics Committee for randomized trials at the University hospital Brno (9/2017, Jihlavska 20, Brno, Czech Republic, Chairperson PharmDr. Kozáková Šárka, MBA) and trial registration in clinicaltrials.gov (NCT03404453), we included patients scheduled for elective diagnostic or surgical procedures under general anaesthesia with the need for airway management (face mask, laryngeal mask, tracheal intubation). 
The study period was from 1. 1. 2018 to 30.6 . 2018. We did not require informed consent for participation according to the decision of the Ethics committee due to the observational design of the trial. We recruited patients during the outpatient pre-anaesthesia evaluation and evaluated them by clinical examination (weight, height) and a panel of prediction test (thyromental distance, upper lip bite test, inter incisor gap, cervical spine mobility and Mallampati score). We measured the distance in centimetres and fold of the patient's middle finger width. We allocated the patient according to the pre anaesthesia evaluation into one of the three groups based on the clinician's decision: A (low risk), B (intermediate risk), C (high risk). In the operating room (OR), the patients were evaluated by the anaesthesiologist just prior to the anaesthesia and they were allocated to three groups (based on the clinician's decision): A, B, C and the airway management plan was defined. After anaesthesia induction and securing the airway, the airway management was evaluated considering the type of induction, type of airway device (face mask, supraglottic device, uncuffed or cuffed tracheal tube), the position of the head, Cormack - Lehane score (during direct laryngoscopy) and number of attempts needed for successful airway. We recorded the incidence of bradycardia (less than 50 beat per minute) and desaturation (oxygen saturation measured by oxygen saturation probe less than $90 \%$ ). The primary outcome was the incidence of DA defined as difficult face mask ventilation, difficult intubation (Cormack-Lehane 3 and 4 , intubation at third and over the third attempt), difficult laryngeal mask insertion (more than two attempts) and the presence of CICO scenario. Events associated with difficult airway (EADA) were defined as at least three attempts needed for airway management, Cormack-Lehane 3-4, difficult intubation, difficult mask ventilation, airway evaluation $\mathrm{B}$ or $\mathrm{C}$ after securing the airway, bronchoscope or videolaryngoscope for airway management, bradycardia during airway management ( $<50$ beats/minute $)$, desaturation $<90 \% \mathrm{SaTO}_{2}$ (measured by pulse oximetry). The secondary outcome was the efficacy of difficult airway prediction during pre-anaesthesia evaluation and before anaesthesia induction. For the statistical analysis, descriptive statistical methods were used (using the $95 \%$ CI, confidence interval). The prediction effectivity was calculated using the Mann-Whitney and Fischer-exact test and using logistic regression analysis for DA and for EADA (using the $P \leq 0.05$ cut-off).

\section{RESULTS}

During the selected period, we included 399 patients in the study and analysed 389 patients after exclusion of 10 cases (insufficient data). The incidence of DA in our cohort was $3.6 \%$ (95\% CI 2.1 to $5.8 \%$ ). There was no statistically significant difference between normal and DA considering the age, weight and height of the patients and all selected prediction tests: Mallampati score, upper lip bite test, thyromental distance, inter incisor gap and cervical spine mobility before anaesthesia induction, clinical evaluation of the airway during the outpatient preanaesthesia evaluation and in the OR (Table 1). The neutral head position was associated with a lower incidence of DA $(P=0.022)$. The age category (infant, toddler, preschool age, young school age, older school age and adolescency) was not associated with overall difficult airway incidence, or DA and/or EADA incidence $(P=0.313$ nad 0.202 ) (Table 2). There was no statistically significant association between clinical parameters, the prediction tests and incidence of DA from the logistic regression analysis (Table 3).

Considering all listed clinically relevant parameters as EADA (at least three attempts needed for airway management, Cormack-Lehane 3-4, difficult intubation, difficult mask ventilation, airway evaluation $\mathrm{B}$ or $\mathrm{C}$ after securing the airway, bronchoscope or videolaryngoscope for airway management, bradycardia during airway management ( $<50$ beats/minute), desaturation $<90 \%$ SaTO2) the incidence of EADA was $10 \%(n=39 / 389,95 \%$ CI 7.3 to $13.3 \%)$. When considering the risk factors for EADA, the only statistically significant difference was patient's airway evaluation in the OR as B $(P=0.005)$ and the head in the wedged position before anaesthesia induction $(P=0.044)$ (Table 4). After logistic regression analysis for EADA incidence, the statistically significant identified risk factors were limited mobility of the cervical spine (limited flexion, limited extension, or free flexion and not recorded extension) with the odds ratio $2.45(P=0.028)$, airway evaluation $B$ in the OR with the odds ratio 6.95 $(P=0.002)$ and neutral head position before anaesthesia induction with odds ratio $0.33(P=0.024)$ (Table 5). The sensitivity of EADA prediction during pre anaesthesia evaluation was $5.3 \%$ (95\% CI 0.1 to $26.0 \%$ ) with specificity of $93.3 \%$ (95\% CI 89.9 to $95.8 \%$ ) which was lower than the EADA prediction during pre-induction evaluation in the OR - sensitivity of $15 \%$ (95\% CI 3.2 to $37.9 \%$ ) and specificity of $97.8 \%$ (95\% CI 95.5 to $99.1 \%$ ).

\section{DISCUSSION}

Airway management difficulties or failure is considered as one major factor associated with perioperative complications ${ }^{1-2}$. Morbidity and mortality in adult and paediatric patients are directly linked to difficult airways $^{14-15}$. Therefore, the anaesthesia providers should be appropriately trained on how to proceed in difficult airway scenarios and local guidelines should be implemented in all anaesthesia centres. The published incidence of difficult airway in paediatric patients is variable given the diversity of DA definition. The reported incidence of difficult airway in paediatric patients is $1 \mathrm{l}^{15}$, but the incidence of difficult bag-mask ventilation may be up to $7 \%$ (ref. ${ }^{16}$ ) and difficult direct laryngoscopy incidence up to $3 \%\left(\right.$ ref. $\left.^{8,17}\right)$. The overall incidence of difficult airway in the selected cohort of patients was $3.6 \%$, which is consistent with previously published data ${ }^{13}$. However, reported airway-related adverse events and mortality in paediatric anaesthesia is higher than in adults ${ }^{2,18}$. This reality in combination with the variable definition of the difficult airway 
Table 1. Prediction tests and clinical evaluation for Normal airway and Difficult airway.

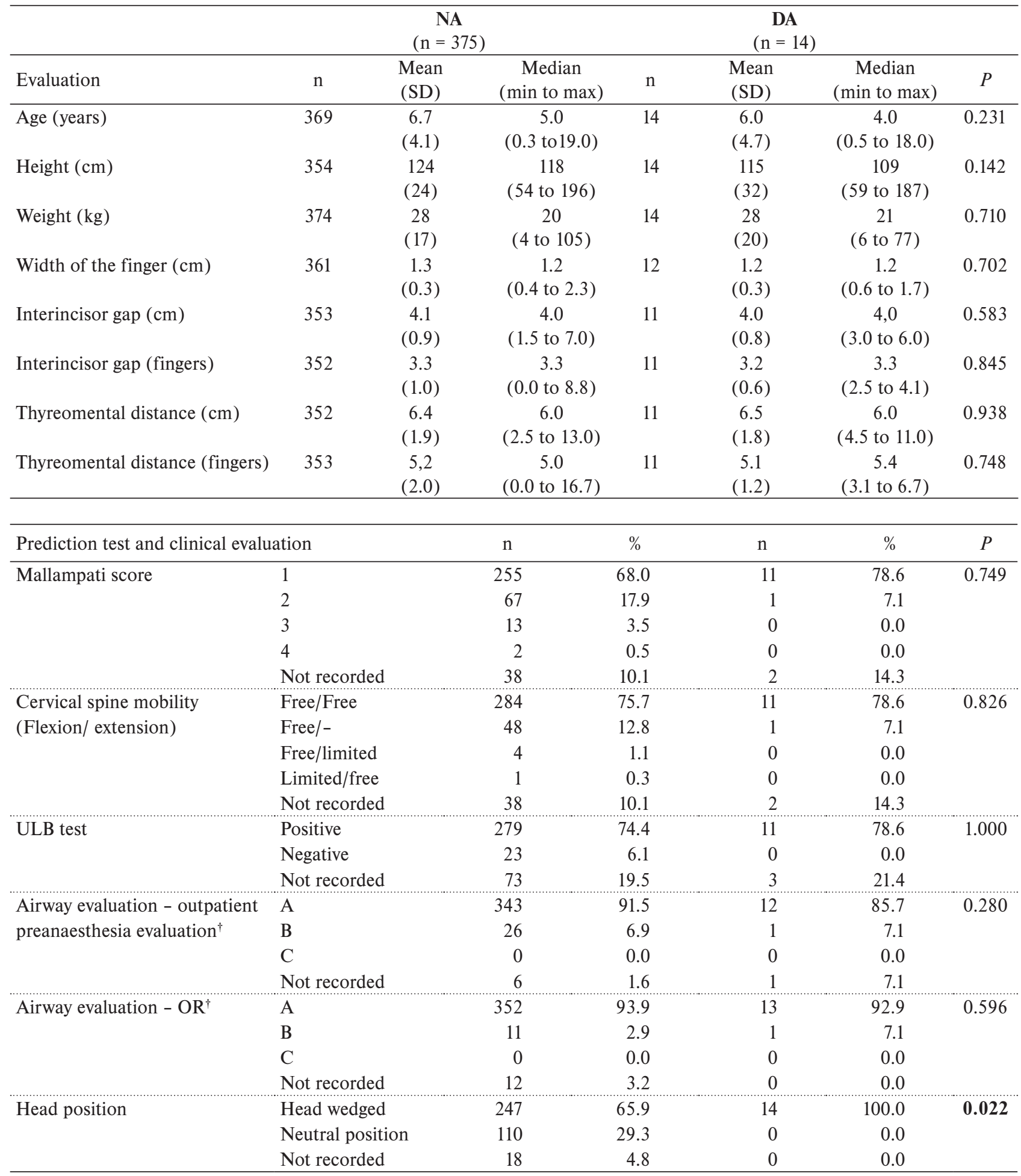

$\mathrm{NA}=$ Normal airway; $\mathrm{DA}=$ Difficult airway; $\mathrm{SD}=$ Standard deviation; $\mathrm{ULB}$ test $=$ Upper lip bite test, $\mathrm{OR}=\mathrm{operating}$ room

$\dagger \mathrm{A}=$ low risk, $\mathrm{B}=$ intermediate risk, $\mathrm{C}=$ high risk

The significant $\mathrm{P}$ values are bolded

led us to extend the definition and compare all clinically relevant adverse events connected with difficult airway management (desaturation, bradycardia) - EADA. When compared to the incidence of DA, the incidence of EADA was far higher $(10.0 \%)$.

The associated risk linked with difficult airway could be partially preventable if patients with difficult airway were identified during the preanaesthesia evaluation and proper preparation was made before anaesthesia ${ }^{19}$. The airway evaluation and patient assessment is an integral part of the preanaesthesia visit ${ }^{20}$. The clinical examination, patient history and medical records should be used to predict airway-related complications and clinical examination of the airways should be performed by the an- 
Table 2. Difficult airway (DA) and Events associated with difficult airway (EADA) incidence according to the age category.

\begin{tabular}{|c|c|c|c|c|c|}
\hline \multirow[t]{2}{*}{ Age category } & \multirow{2}{*}{$\begin{array}{l}\text { Difficult } \\
\text { airway }\end{array}$} & \multicolumn{2}{|r|}{ DA } & \multicolumn{2}{|c|}{ EADA } \\
\hline & & $\mathrm{n}$ & $\%(95 \% \mathrm{CI})$ & $\mathrm{n}$ & $\%(95 \% \mathrm{CI})$ \\
\hline \multirow{2}{*}{$\begin{array}{l}\text { All patients } \\
(\mathrm{n}=389)^{*}\end{array}$} & No & 375 & $96.4(94.2-97.9)$ & 350 & $90.0(86.7-92.7)$ \\
\hline & Yes & 14 & $3.6(2.1-5.8)$ & 39 & $10.0(7.3-13.3)$ \\
\hline \multirow{2}{*}{$\begin{array}{l}\text { Infant - do } 1 \text { years } \\
(n=2)\end{array}$} & No & 1 & $50.0(6.1-93.9)$ & 1 & $50.0(6.1-93.9)$ \\
\hline & Yes & 1 & $50.0(6.1-93.9)$ & 1 & $50.0(6.1-93.9)$ \\
\hline \multirow{2}{*}{$\begin{array}{l}\text { Toddler }-1-2 \text { years } \\
(\mathrm{n}=18)\end{array}$} & No & 18 & $100.0(-)$ & 18 & $100.0(-)$ \\
\hline & Yes & 0 & $0.0(-)$ & 0 & $0.0(-)$ \\
\hline \multirow{2}{*}{$\begin{array}{l}\text { Preschool age }-3-5 \text { years } \\
(n=184)\end{array}$} & No & 176 & $95.7(92.0-97.9)$ & 165 & $89.7(84.7-93.5)$ \\
\hline & Yes & 8 & $4.3(2.1-8.0)$ & 19 & $10.3(6.5-15.3)$ \\
\hline \multirow{2}{*}{$\begin{array}{l}\text { Younger school age }-6-10 \text { years } \\
(n=115)\end{array}$} & No & 112 & $97.4(93.2-99.3)$ & 104 & $90.4(84.1-94.8)$ \\
\hline & Yes & 3 & $2.6(0.7-6.8)$ & 11 & $9.6(5.2-15.9)$ \\
\hline \multirow{2}{*}{$\begin{array}{l}\text { Older school age - 11-14 years } \\
(\mathrm{n}=38)\end{array}$} & No & 37 & $97.4(88.4-99.7)$ & 33 & $86.8(73.5-94.8)$ \\
\hline & Yes & 1 & $2.6(0.3-11.6)$ & 5 & $13.2(5.2-26.5)$ \\
\hline \multirow{3}{*}{$\begin{array}{l}\text { Adolescency - } 15-19 \text { years } \\
(\mathrm{n}=26)\end{array}$} & No & 25 & $96.2(83.4-99.6)$ & 23 & $88.5(72.3-96.6)$ \\
\hline & Yes & 1 & $3.8(0.4-16.6)$ & 3 & $11.5(3.4-27.7)$ \\
\hline & $P$ & 0.313 & & 0.202 & \\
\hline
\end{tabular}

* 6 patients was excluded from analysis due to missing data, DA = Difficult airway; EADA = Events associated with difficult airway

Table 3. Logistic regression analysis for DA prediction and DA incidence.

\begin{tabular}{|c|c|c|c|c|c|}
\hline \multicolumn{2}{|c|}{ Clinical parameters and prediction tests } & $\mathrm{n}$ & odds ratio & $95 \% \mathrm{CI}$ for odds ratio & $P$ \\
\hline \multicolumn{2}{|l|}{ Age (increase by 1 year) } & 383 & 0.95 & 0.82 to 1.10 & 0.524 \\
\hline \multicolumn{2}{|l|}{ Height (increase by $10 \mathrm{~cm}$ ) } & 368 & 0.84 & 0.65 to 1.09 & 0.184 \\
\hline \multicolumn{2}{|l|}{ Weight (increase by 5 kg) } & 388 & 1.01 & 0.87 to 1.17 & 0.929 \\
\hline \multicolumn{2}{|c|}{ Interincisor gap (increase by 1 finger width) } & 363 & 0.83 & 0.42 to 1.67 & 0.605 \\
\hline \multicolumn{2}{|c|}{ Thyreomental distance (increase by 1 finger width) } & 364 & 0.99 & 0.72 to 1.35 & 0.936 \\
\hline \multirow[t]{2}{*}{ Mallampati score } & 1 & 266 & 1,00 & - & - \\
\hline & $2-4$ & 83 & 0.28 & 0.04 to 2.22 & 0.230 \\
\hline \multirow{2}{*}{$\begin{array}{l}\text { Cervical spine mobility } \\
\text { (flexion/extension) }\end{array}$} & free/free & 295 & 1.00 & - & - \\
\hline & $\begin{array}{l}\text { Limited flexion or extension, } \\
\text { or free flexion/NR extension }\end{array}$ & 54 & 0.49 & 0.06 to 3.85 & 0.495 \\
\hline \multirow[t]{2}{*}{ ULB test } & Positive & 290 & \multirow{2}{*}{\multicolumn{3}{|c|}{ Cannot be calculated }} \\
\hline & Negative & 23 & & & \\
\hline \multirow{2}{*}{$\begin{array}{l}\text { Airway evaluation - outpatient } \\
\text { preanaesthesia evaluation }^{\dagger}\end{array}$} & A & 355 & 1.00 & - & - \\
\hline & B & 27 & 1.10 & 0.14 to 8.79 & 0.929 \\
\hline \multirow[t]{2}{*}{ Airway evaluation - $\mathrm{OR}^{\dagger}$} & A & 365 & 1.00 & - & - \\
\hline & B & 12 & 2.46 & 0.30 to 20.52 & 0.405 \\
\hline \multirow[t]{2}{*}{ Head position } & Head wedged & 261 & \multicolumn{3}{|c|}{ Cannot be calculated } \\
\hline & Head neutral position & 110 & & & \\
\hline
\end{tabular}

$\mathrm{DA}=$ Difficult airway; $\mathrm{CI}=$ Confidential interval; ULB test $=$ Upper lip bite test; $\mathrm{OR}=$ operating room; $\mathrm{NR}=$ not recorded $\uparrow \mathrm{A}=$ low risk, $\mathrm{B}=$ intermediate risk

aesthesiologist (mouth opening, cervical spine mobility, etc. $)^{21}$. Multiple clinical examinations and tests have been explored for difficult airway prediction. Several difficult airway prediction scores and scales have been used in paediatric population without validation ${ }^{21}$. Although published data describe difficult paediatric airway as easy to predict $^{13}$, no single prediction test (or combination), clinical evaluation or examintation of the airway has the ability to provide a positive prediction. In our cohort only limited cervical spine mobility was associated with very low difficult airway prediction probability. In the literature, several potential risk factors are mentioned such as weight, weight $<10 \mathrm{~kg}$, age and short thyreomental distance ${ }^{14}$. The decreasing age of paediatric patients are described as a potential risk factor ${ }^{15}$, however in our study overall age, age category (infant, toddler, preschool, basic 
Table 4. Prediction test and clinical evaluation for EADA.

\begin{tabular}{|c|c|c|c|c|c|c|c|}
\hline \multirow[b]{2}{*}{ Evaluation } & \multirow[b]{2}{*}{$\mathrm{n}$} & \multicolumn{2}{|c|}{$\begin{array}{c}\text { NA } \\
(\mathrm{n}=350)\end{array}$} & \multicolumn{3}{|c|}{$\begin{array}{c}\text { EADA } \\
(\mathrm{n}=39)\end{array}$} & \multirow[b]{2}{*}{$P$} \\
\hline & & $\begin{array}{l}\text { Mean } \\
\text { (SD) }\end{array}$ & $\begin{array}{c}\text { Median } \\
\text { (min to } \max \text { ) }\end{array}$ & $\mathrm{n}$ & $\begin{array}{l}\text { Mean } \\
\text { (SD) }\end{array}$ & $\begin{array}{c}\text { Median } \\
\text { (min to } \max )\end{array}$ & \\
\hline Age (years) & 344 & $6.6(4,0)$ & $5.0(0.3$ to 19.0$)$ & 39 & $7.1(4.5)$ & $5.0(0.5$ to 18.0$)$ & 0.648 \\
\hline Height $(\mathrm{cm})$ & 331 & $123(24)$ & $118(54$ to 196$)$ & 37 & $123(29)$ & 118 (59 to 187$)$ & 0.874 \\
\hline Weight (kg) & 349 & $27(17)$ & $20(4$ to 105$)$ & 39 & $30(20)$ & $22(6$ to 80$)$ & 0.385 \\
\hline Width of the finger $(\mathrm{cm})$ & 336 & $1.3(0,3)$ & $1.2(0.4$ to 2.3$)$ & 37 & $1.3(0.3)$ & $1.2(0.6$ to 2.0$)$ & 0.905 \\
\hline Interincisor gap $(\mathrm{cm})$ & 329 & $4.1(0.9)$ & $4.0(1.5$ to 7.0$)$ & 35 & $4.1(1.0)$ & $4.0(3.0$ to 7.0$)$ & 0.487 \\
\hline Interincisor gap (fingers) & 328 & $3.3(1.0)$ & $3.3(0.0$ to 8.8$)$ & 35 & $3.2(0.6)$ & $3.3(2.3$ to 5.0$)$ & 0.596 \\
\hline Thyreomental distance $(\mathrm{cm})$ & 328 & $6.4(1.9)$ & $6.0(2.5$ to 13.0$)$ & 35 & $6.7(2.0)$ & $6.0(4.5$ to 12.0$)$ & 0.542 \\
\hline Thyreomental distance (fingers) & 329 & $5.2(2.0)$ & $5.0(0.0$ to 16.7$)$ & 35 & $5.3(1.4)$ & $5.0(3.1$ to 10.0$)$ & 0.296 \\
\hline
\end{tabular}

\begin{tabular}{|c|c|c|c|c|c|c|}
\hline Prediction test and clinical evaluation & & $\mathrm{n}$ & $\%$ & $\mathrm{n}$ & $\%$ & $P$ \\
\hline \multirow[t]{5}{*}{ Mallampati score } & 1 & 240 & 68.6 & 26 & 66.7 & 0.690 \\
\hline & 2 & 59 & 16.9 & 9 & 23.1 & \\
\hline & 3 & 13 & 3.7 & 0 & 0.0 & \\
\hline & 4 & 2 & 0.6 & 0 & 0.0 & \\
\hline & Not recorded & 36 & 10.3 & 4 & 10.3 & \\
\hline \multirow[t]{5}{*}{ Cervical spine mobility (flexion/ extension) } & Free/Free & 270 & 77.1 & 25 & 64.1 & 0.154 \\
\hline & Free/- & 40 & 11.4 & 9 & 23.1 & \\
\hline & Free/limited & 3 & 0.9 & 1 & 2.6 & \\
\hline & Limited/free & 1 & 0.3 & 0 & 0.0 & \\
\hline & Not recorded & 36 & 10.3 & 4 & 10.3 & \\
\hline \multirow[t]{3}{*}{ ULB test } & Positive & 260 & 74.3 & 30 & 76.9 & 1.000 \\
\hline & Negative & 21 & 6.0 & 2 & 5.1 & \\
\hline & Not recorded & 69 & 19.7 & 7 & 17.9 & \\
\hline \multirow[t]{4}{*}{ Airway evaluation - outpatient preanaesthesia evaluation ${ }^{\dagger}$} & A & 321 & 91.7 & 34 & 87.2 & 0.356 \\
\hline & $\mathrm{B}$ & 23 & 6.6 & 4 & 10.3 & \\
\hline & $\mathrm{C}$ & 0 & 0.0 & 0 & 0.0 & \\
\hline & Not recorded & 6 & 1.7 & 1 & 2.6 & \\
\hline \multirow[t]{4}{*}{ Airway evaluation - $\mathrm{OR}^{\dagger}$} & A & 331 & 94.6 & 34 & 87.2 & 0.005 \\
\hline & $\mathrm{B}$ & 7 & 2.0 & 5 & 12.8 & \\
\hline & $\mathrm{C}$ & 0 & 0.0 & 0 & 0.0 & \\
\hline & Not recorded & 12 & 3.4 & 0 & 0.0 & \\
\hline \multirow[t]{3}{*}{ Head position } & Head wedged & 228 & 65.1 & 33 & 84.6 & 0.044 \\
\hline & Neutral position & 105 & 30.0 & 5 & 12.8 & \\
\hline & Not recorded & 17 & 4.9 & 1 & 2.6 & \\
\hline
\end{tabular}

EADA = Events associated with difficult airway; NA = Normal airway; SD = Standard deviation; ULB test = Upper lip bite test, $\mathrm{OR}=$ operating room

$\dagger \mathrm{A}=$ low risk, $\mathrm{B}=$ intermediate risk, $\mathrm{C}=$ high risk

The significant $P$ values are bolded

school, adolescence) were statistically related to the DA or EADA incidence (Table 1 and Table 2). Difficult airway is directly linked with the syndromic and dysmorphic features such as Pierre Robin sequence, Treacher Collins syndrome, Goldenhar syndrome, mucopolysaccharidosis and others ${ }^{14,22-23}$. These patients, however represent only a minority of paediatric patients scheduled for acute or elective surgeries in paediatric anaesthesia centres.

Considering the extended EADA criteria, DA in our cohort was associated with the wedged position of the head, limited mobility of the cervical spine and could be predicted from the clinical evaluation of the anaesthesi- ologist in the operating room, however with a sensitivity of only $15 \%$. The efficacy the DA prediction of the anaesthesiologist during outpatient pre-anaesthesia evaluation was even weaker ( $P=0.929$ vs $P=0.405$ for DA and $P=0.385$ vs $P=0.002$ for EADA). The limited DA predictability can be partially explained by the absence of validation of the majority of prediction tests on the paediatric population. It should be noted that although some data find paediatric difficult airway rare and easy to predict ${ }^{15,24}$, the reported incidence of difficult bag mask ventilation is up to $7 \%{ }^{16}$ and difficult direct laryngoscopy up to $3 \%$ (ref. ${ }^{17}$ ) (or even up to $4.7 \%$ in infants) (ref. ${ }^{3,8}$ ). 
Table 5. Logistic regression analysis for EADA prediction and EADA incidence.

\begin{tabular}{|c|c|c|c|c|c|}
\hline \multicolumn{2}{|c|}{ Clinical parameters and prediction tests } & $\mathrm{n}$ & Odds ratio & $\begin{array}{c}95 \% \mathrm{CI} \\
\text { for odds ratio }\end{array}$ & $P$ \\
\hline \multicolumn{2}{|l|}{ Age (increase by 1 year) } & 383 & 1.03 & 0.96 to 1.11 & 0.425 \\
\hline \multicolumn{2}{|l|}{ Height (increase by $10 \mathrm{~cm}$ ) } & 368 & 0.99 & 0.86 to 1.14 & 0.931 \\
\hline \multicolumn{2}{|l|}{ Weight (increase by $5 \mathrm{~kg}$ ) } & 388 & 1.04 & 0.95 to 1.13 & 0.363 \\
\hline \multicolumn{2}{|c|}{ Interincisor gap (increase by 1 finger width) } & 363 & 0.85 & 0.57 to 1.26 & 0.411 \\
\hline \multicolumn{2}{|c|}{ Thyreomental distance (increase by 1 finger width) } & 364 & 1.04 & 0.88 to 1.23 & 0.672 \\
\hline \multirow{2}{*}{ Mallampati score } & 1 & 266 & 1.00 & - & - \\
\hline & $2-4$ & 83 & 1.12 & 0.50 to 2.50 & 0.777 \\
\hline \multirow{2}{*}{$\begin{array}{l}\text { Cervical spine mobility } \\
\text { (flexion/extension) }\end{array}$} & free/free & 295 & 1.00 & - & - \\
\hline & $\begin{array}{l}\text { Limited flexion or extension, } \\
\text { or free flexion/NR extension }\end{array}$ & 54 & 2.45 & 1.10 to 5.46 & 0.028 \\
\hline \multirow[t]{2}{*}{ ULB test } & Positive & 290 & 1.00 & - & - \\
\hline & Negative & 23 & 0.83 & 0.18 to 3.69 & 0.802 \\
\hline \multirow{2}{*}{$\begin{array}{l}\text { Airway evaluation - outpatient } \\
\text { preanaesthesia evaluation }^{\dagger}\end{array}$} & A & 355 & 1.00 & - & - \\
\hline & $\mathrm{B}$ & 27 & 1.64 & 0.54 to 5.03 & 0.385 \\
\hline \multirow[t]{2}{*}{ Airway evaluation - $\mathrm{OR}^{\dagger}$} & A & 365 & 1.00 & - & - \\
\hline & $\mathrm{B}$ & 12 & 6.95 & 2.09 to 23.10 & 0.002 \\
\hline \multirow[t]{2}{*}{ Head position } & Head wedged & 261 & 1.00 & - & - \\
\hline & Head neutral position & 110 & 0.33 & 0.12 to 0.87 & 0.024 \\
\hline
\end{tabular}

$\mathrm{EADA}=$ Events associated with difficult airway; ULB test $=$ Upper lip bite test, $\mathrm{OR}=$ operating room, NR $=$ Not recorded $\dagger \mathrm{A}=$ low risk, $\mathrm{B}=$ intermediate risk

The significant $P$ values are bolded

The major limitation of the study is the observational design and the limited number of patients. Despite this limitation, the incidence of $3.6 \%$ of DA and $10 \%$ for EADA in combination with very limited DA predictability is surprising and demands standardisation of airway evaluation and difficult airway prediction in paediatric anaesthesiology. The main contribution of the study is that despite the low DA incidence (3.6\%), the clinically more important EADA incidence was significantly higher (10\%), with only minimal options for DA or EADA prediction.

\section{CONCLUSION}

Difficult airway incidence in a selected cohort of paediatric patients was $3.6 \%$, and clinically more relevant incidence of events associated with difficult airways (including bradycardia and desaturation during induction) was $10 \%$ with only minimal options for prediction.

\section{ABBREVIATIONS}

ASA, American Society of Anesthesiology; BMI, Body mass index; CI, Confidence interval; CICO, Cannot intubate/ cannot oxygenate; DA, Difficult airway; EADA, Events associated with difficult airway; ENT, Ear Nose Throat; OR, Operating room.

Acknowledgment: Financial support and sponsorship: The study was supported by a Specific University Research provided by MŠMT (MUNI/A/1111/2018 and
MUNI/A/0943/2019), supported by MH CZ - DRO (FNBr, 65269705) and supported by funds from the Faculty of Medicine MU to the junior researcher (Jozef Klučka, Martina Kosinová, ROZV/28/LF/2020).

Author contributions: JK, MKo, MKr, MT, RS, IK, LM, MU, PS: were responsible for data collection; JK, MKo, MKr, PS: data analysis; PK, MH, TP: statistical analyses; JK, MKo, MKr, MT, RS, IK, LM, PS: final version of article. All authors approved the final version of the article. All authors have met the criteria for authorship according to the ICMJE criteria.

Conflict of interest statement: The authors state that there are no conflicts of interest regarding the publication of this article.

\section{REFERENCES}

1. Bhananker SM, Ramamoorthy C, Geiduschek JM, Posner KL, Domino KB, Haberkern CM, Campos JS, Morray JP. Anesthesia-related cardiac arrest in children: update from the Pediatric Perioperative Cardiac Arrest Registry. Anesth Analg 2007;105(2):344-50.

2. Jimenez N, Posner KL, Cheney FW, Caplan RA, Lee LA, Domino KB. An update on pediatric anesthesia liability: a closed claims analysis. Anesth Analg 2007;104(1):147-53.

3. Murat I, Constant I, Maud'huy H. Perioperative anaesthetic morbidity in children: a database of 24,165 anaesthetics over a 30-month period. Paediatr Anaesth 2004;14(2):158-66.

4. Mamie C1, Habre W, Delhumeau C, Argiroffo CB, Morabia A. Incidence and risk factors of perioperative respiratory adverse events in children undergoing elective surgery. Paediatr Anaesth 2004;14(3):218-24.

5. Klučka J, Štourač P, Štoudek R, Ťoukálková M, Harazim H, Kosinová M. Controversies in Pediatric Perioperative Airways. Biomed Res Int 2015;2015:368761. doi: 10.1155/2015/368761

6. Karkouti K, Rose DK, Wigglesworth D, Cohen MM. Predicting difficult intubation: a multivariable analysis. Can J Anaesth 2000;47(8):730-9. 
7. Frei FJ, Ummenhofer W. Difficult intubation in paediatrics. Paediatr Anaesth 1996;6(4):251-63.

8. Heinrich S, Birkholz T, Ihmsen H, Irouschek A, Ackermann A, Schmidt $J$. Incidence and predictors of difficult laryngoscopy in 11,219 pediatric anesthesia procedures. Paediatr Anaesth 2012;22(8):729-36.

9. Heinrich S, Birkholz T, Irouschek A, Ackermann A, Schmidt J. Incidences and predictors of difficult laryngoscopy in adult patients undergoing general anesthesia : a single-center analysis of 102,305 cases. J Anesth 2013;27(6):815-21.

10. Russo SG1, Becke K. Expected difficult airway in children. Curr Opin Anaesthesiol 2015;28(3):321-6.

11. Apfelbaum JL, Hagberg CA, Caplan RA, Blitt CD, Connis RT, Nickinovich DG, Hagberg CA, Caplan RA, Benumof JL, Berry FA, Blitt CD, Bode RH, Cheney FW, Connis RT, Guidry OF, Nickinovich DG, Ovassapian A; American Society of Anesthesiologists Task Force on Management of the Difficult Airway. Practice guidelines for management of the difficult airway: an updated report by the American Society of Anesthesiologists Task Force on Management of the Difficult Airway. Anesthesiology 2013;118(2):251-70.

12. Black AE1, Flynn PE, Smith HL, Thomas ML, Wilkinson KA; Association of Pediatric Anaesthetists of Great Britain and Ireland. Development of a guideline for the management of the unanticipated difficult airway in pediatric practice. Paediatr Anaesth 2015;25(4):346-62

13. Weiss M1, Engelhardt T. Proposal for the management of the unexpected difficult pediatric airway. Paediatr Anaesth 2010;20(5):45464.

14. Fiadjoe JE, Nishisaki A, Jagannathan N, Hunyady Al, Greenberg RS, Reynolds PI, Matuszczak ME, Rehman MA, Polaner DM, Szmuk P Nadkarni VM, McGowan FX Jr, Litman RS, Kovatsis PG. Airway management complications in children with difficult tracheal intubation from the Pediatric Difficult Intubation (PeDI) registry: a prospective cohort analysis. Lancet Respir Med 2016;4(1):37-48. doi: 10.1016/ S2213-2600(15)00508-1

15. Huang AS, Hajduk J, Rim C, Coffield S, Jagannathan N. Focused review on management of the difficult paediatric airway. Indian J Anaesth 2019;63(6):428-36.

16. Valois-Gomez T, Oofuvong M, Auer G, Coffin D, Loetwiriyakul W, Correa JA. Incidence of difficult bagmask ventilation in children: A prospective observational study. Paediatr Anaesth 2013;23(10):9206.

17. Heidegger T, Gerig HJ, Ulrich B, Kreienbuhl G. Validation of a simple algorithm for tracheal intubation: Daily practice is the key to success in emergencies - an analysis of 13,248 intubations. Anesth Analg 2001;92:517-22.

18. Morray JP, Geiduschek JM, Caplan RA, Posner KL, Gild WM, Cheney FW. A comparison of pediatric and adult anesthesia closed malpractice claims. Anesthesiology 1993;78(3):461-7.

19. Cook TM,Woodall N, Frerk C; Fourth National Audit Project. Major complications of airway management in the UK: results of the Fourth National Audit Project of the Royal College of Anaesthetists and the Difficult Airway Society. Part 1: anaesthesia. Br J Anaesth 2011;106(05):617-31.

20. Sunder RA, Haile DT, Farrell PT, Sharma A. Pediatric airway management: current practices and future directions. Paediatr Anaesth 2012;22(10):1008-15.

21. Krishna SG, Bryant JF, Tobias JD. Management of the Difficult Airway in the Pediatric Patient. Pediatr Intensive Care 2018;7:115-25.

22. Butler MG, Hayes BG, Hathaway MM, Begleiter ML. Specific genetic diseases at risk for sedation/anesthesia complications. Anesth Analg 2000;91(04):837-55.

23. Uezono S, Holzman RS, Goto T, Nakata Y, Nagata S, Morita S. Prediction of difficult airway in school-aged patients with microtia. Paediatr Anaesth 2001;11(04):409-13.

24. Pawar DK, Doctor JR, Raveendra US, Ramesh S, Shetty SR, Divatia JV, Myatra SN, Shah A, Garg R, Kundra P, Patwa A, Ahmed SM, Das S, Ramkumar V. All India Difficult Airway Association 2016 guidelines for the management of unanticipated difficult tracheal intubation in Paediatrics. Indian J Anaesth 2016;60(12):906-14. 